\title{
On Doing Ontology without Metaphysics
}

\author{
Achille C. Varzi \\ Department of Philosophy, Columbia University, New York
}

[Final version published in Philosophical Perspectives 25 (2011), 407-423]

\section{Introduction}

According to a certain, familiar way of dividing up the business of philosophy, made popular by Quine, ontology is concerned with the question of what entities exist (a task that is often identified with that of drafting a "complete inventory" of the universe) whereas metaphysics seeks to explain, of those entities, what they are (i.e., to specify the "ultimate nature" of the items included in the inventory). ${ }^{1}$ For instance, a thesis to the effect that there are such things as colors or virtues would strictly speaking belong to ontology, whereas it would pertain to metaphysics proper to establish whether such entities are Platonic forms, immanent universals, tropes, moments, or what have you. Likewise, it would fall within the scope of ontology to determine whether, when we speak of Sherlock Holmes, of the natural numbers, or of Sebastian's walks in Bologna, we are truly speaking of things that belong to the furniture of the universe, but it would be a further metaphysical task to say something precise in regard to the ultimate make-up of those things, if such there be-for instance, that Sherlock Holmes is a theoretical artifact, that numbers are abstract individuals, that walks are property exemplifications, and so on.

Of course, this view is everything but universal among philosophers. There are many other, different ways of understanding the terms 'ontology' and 'metaphysics', some of which can certainly claim a respectable pedigree. For example, it is also common to think of ontology as a proper part of metaphysics - that part that has to do with what there is ${ }^{2}$ - and there are even philosophers who use those terms in a way that is the exact opposite of the one I have just offered. ${ }^{3}$ But never mind; I am not interested in defending the view or in criticizing it, as very little depends on it. I am citing it just to fix a certain distinction and to settle on a terminology. The question I wish to address concerns the relationship between the distinction - the relationship between ontology understood as the study of what there is and metaphysics understood as the study of what it is. I have always thought that the distinction carries with it a natural thought, namely, that ontology is in 
some way prior to metaphysics. One must first of all figure out what things exist (or might exist); then one can attend to the further question of what they are, specify their nature, speculate on those features that make each thing the thing it is. Let us call this the priority thesis. I don't think many philosophers have endorsed it explicitly, let alone argued for its truth. Nonetheless there is, I think, good evidence that the priority thesis has been driving much philosophical work. Already Aristotle, for instance, was thinking along these lines, at least in some of his writings. A good example may be found in the Posterior Analytics, where he says that we must not only seek the facts and the reasons why, but also if something is or is not, 'and knowing that it is, we seek what it is (e.g., so what is a god? or what is a man?)' [II, 2, 89b34-35]. Thomas Aquinas was equally explicit in the Summa Theologiae, when he said that we must first establish whether God exists (an sit Deus) and then ask what he is (quid Deus sit) - a further question which, in his opinion, cannot in fact be answered [I, q.2, a.2, ad 2]. And what goes for God goes for everything. It is only on the assumption that numbers exist, for example, that Paul Benacerraf famously raised the question of what they could be (or not be). ${ }^{4}$ It is on the assumption that events are genuine denizens of reality that Donald Davidson, Roderick Chisholm, Jaegwon Kim, and others embarked in endless querrels concerning their nature and identity conditions. ${ }^{5}$ And it is generally on the assumption that persons exist that monists and dualists, essentialists and conventionalists, or endurantists and perdurantists engage in ever more lively debates on what persons are and how they differ from other existents.

As I said, I sympathize with all this. Pace Descartes, who said that putting the an sit before the quid sit would violate "the laws of true logic", 6 I have always found that the priority thesis captures a natural thought, a practical necessity if not a norm, and I have always valued its guidance in assessing actual philosophical disagreements. ${ }^{7}$ I must say, however, that today the picture strikes me as more problematic than I used to admit. I still sympathize with the thesis, along with the sharp distinction between ontology and metaphysics that it presupposes. Yet there is a major worry lurking in the background, and there are several complications that emerge in the foreground. My purpose, here, is to address such worries and complications, and to come up with a plausible way of understanding the thesis that makes it both reasonable and, hopefully, useful.

\section{The Main Worry}

Let me begin with the main worry, and with the answer that I think can be offered. I will do so with the help of an example. 
Suppose that two philosophers, Alpha and Beta, have fully worked out their ontological credos. In other words, suppose that each has managed to draw up a comprehensive inventory of all there is, which is to say: all he or she thinks there is. (How one goes about doing that is by itself a hairy issue, but let us suppose that our two philosophers have a method. Perhaps they first figured out their overall beliefs about the world and then looked for the underlying truth-makers; perhaps they reflected directly on their experience of the world; perhaps they relied on thought experiments, indispensability arguments, inference to the best explanation.) In particular, let us suppose that both have included in their respective inventories ordinary material objects such as statues, tables, apples, mountains, marble blocks, straw stacks, and so on. According to the priority thesis, at this point Alpha and Beta should be able to move on and work out their metaphysical credos by specifying the nature of such things, and nothing prevents them from parting company: they could agree that such things exist while disagreeing on what they are. (Otherwise their metaphysics would not follow their ontology; it would follow from their ontology, i.e., it would be determined by it.) For instance, both might agree on the reality of Michelangelo's David while disagreeing in regard to its conditions of persistence through time: Alpha might be an endurantist whereas Beta might side with the perdurantists. Or they might disagree in regard to David's "essential" properties: Alpha might think that David is necessarily constituted by that piece of marble, whereas Beta might think that David's material constitution is just an accidental feature: Michelangelo might have carved it out of a different block of marble, if not from a block of cheese. They might also disagree on whether David is a primitive, irreducible entity as opposed to a derived or dependent one, say a bundle of properties, or a bundle cum substratum. In short, according to the priority thesis, Alpha and Beta are free to articulate the metaphysics of material objects that they prefer and as they see fit - and here comes the worry. Surely there is an important sense in which our two philosophers could be said to share the same ontology, at least partly: both acknowledge the existence of ordinary material objects, among which Michelangelo's David. It is also apparent, however, that they have radically different opinions regarding such things. In what sense, then, is it plausible to consign this divergence to a metaphysical sphere that would only start spinning when the ontological sphere comes to a rest? How can we say that Alpha's and Beta's inventories include the same entities, if the entities they include are metaphysically different?

This is just an example. But similar considerations would apply to any sort of entity that our two philosophers might treat with equal ontological dignity. Generally speaking, agreeing on what existential assertions are true does not warrant 
a corresponding agreement concerning the entities that make them true. Hence, the boundary between the an sit and the quid sit would seem to collapse and Descartes's complaint would strike back: one cannot truly fix an ontology without also, and at the same time, accepting or presupposing specific metaphysical views.

\section{Reply}

This is more than a worry, of course. It is a serious objection, and it would by itself suffice to discard the priority thesis along with the philosophical distinction on which it rests. Nonetheless, this line of thinking admits of a legitimate responseactually two.

The first and quick response is simply that there is nothing incoherent in the idea that two people - two philosophers - may have different opinions concerning one and the same entity. This is obvious in the case of ordinary opinions. For you the statue of David is splendid; for me it isn't. It doesn't follow that we are referring to two distinct Davids - one splendid and one unimpressive. We may have contrasting opinions in the context of scientific theorizing, too. For Newton, light was a stream of particles; for Huygens, it was a form of wave motion. It does not follow that Newton and Huygens were talking across each other. Well then, the same could be said of contrasting opinions in metaphysics, except that it might be difficult, if not impossible, to determine who is right. Alpha and Beta have different opinions concerning the nature of Michelangelo's David? It doesn't follow that they are speaking of different things; they may just disagree on what that one thing is. As with you and me, or with Newton and Huygens, Alpha and Beta need not be talking across each other. They may sincerely assert the existence of the same thing-David — well before embarking in metaphysical speculations concerning its ultimate nature. (Compare: If an oracle told us that the correct metaphysic is perdurantist, as Beta holds, it is reasonable to suppose that Alpha would not react by denying the existence of David. Simply, Alpha would accept the news and revise her views accordingly. This is, after all, what we all try to achieve when we argue with our colleagues: we all try to make them change their views on a certain subject, not to change the subject. In a way, this is also the lesson of Putnam's arguments concerning the theoretical status of scientific terms: Renaissance people used to think that water was one of the simple elements of which the sublunar world is composed; with Lavoisier we came to recognize that water is instead a compound of hydrogen and oxygen. Surely that is called progress. Otherwise we would have to conclude that Michelangelo thought he was drinking something else than what we think we are drinking. ${ }^{8}$ ) 
This way of seeing things is confirmed, I think, by much philosophical practice that goes far beyond the example at issue. As I mentioned at the beginning, when two philosophers debate on the metaphysics of persons, for instance, they often take it for granted that they are agreeing on the object of their disagreement; they agree that there are persons and also on which things qualify as persons. It is when they begin questioning the nature of such entities - their persistence conditions, the relationship between a person and her body, and so on-that their views may begin to diverge. Or think of the "species problem" in the philosophy of biology. One may or may not agree that species are real entities (as opposed to theoretical constructs of some sort). But it seems to me than when two philosophers do agree on the reality of Homo sapiens, for instance, there is genuine ontological agreement even if our philosophers may not be inclined to favor the same metaphysical account (one may think that Homo sapiens is a set of individuals while the other may think that Homo sapiens is itself an individual, albeit composed of many scattered organisms ${ }^{9}$ ). Indeed, I would say that the search for a good metaphysics of biological species can only be driven by the fact that we already know what we are talking about, for example, that the species Homo sapiens has a certain extension: as Hugh Paterson put it, when we trade ideas in biology, species are "our currency", and it is with the value of that currency that one must come to terms. ${ }^{10}$ Or again — speaking of currency — think of the recent debate on the ontology and metaphysics of social reality. Few would doubt that there are such things as dollar bills, passports, traffic lights, universities, weddings, nations, and so on. But when it comes to saying what they really are, there is plenty of room for disagreement. $^{11}$ (Even Marx's treatment of commodities - the category of social objects that is the focus of no less than The Capital-begins with the claim that the analysis of such things shows them to be, in reality, "very queer things, abounding in metaphysical subtleties'. ${ }^{12}$ ) In short, I do not mean to deny that in some cases there may be lack of clarity in the way we answer the ontological question, but on the whole it seems to me that philosophical practice confirms to the priority thesis. At least, it lends support to the claim that the thesis is coherent: we may agree on the ontology and disagree on the metaphysics.

One might reply that lack of clarity in at least some cases is enough to refute the thesis. For instance, often the question, 'Do you believe in the existence of God?', receives the answer, 'It depends on what you mean by 'God', and that may be taken to suggest that, pace Aquinas, here the an sit comes after the quid sit, not before. This is, after all, the reason why A. J. Ayer concluded that it makes no sense at all to speak of God's existence, for he thought that the concept of God is meaningless. ${ }^{13}$ Fair enough. I am not saying that this way of putting things is 
incoherent; my aim is to make sense of the opposite view. And to that end, I would here insist that there is a big difference between asking what God is and asking what is meant by 'God', or what our concept of God amounts to. If someone told me that she is using this word to refer to the creator of heaven and earth, or to an omnipotent being, I would have no difficulty in making up my mind concerning the existence or non-existence of something that fits the bill. Yet such definitions have no metaphysical content, on pain of degrading metaphysics to the point of saying that any attribution of properties falls within its province. Such definitions tell me nothing about the nature of God; they just give me some instructions to go and see whether my inventory of all there is includes a certain item. They are identifying descriptions, if you like, not characterizing descriptions. And it wouldn't change much if the meaning of 'God' were explained through a definition packed with robust metaphysical jargon: as an elucidation of the meaning of a word, such an explanation would not belong to metaphysics but to the semantics of our language, and it would be a bad explanation precisely because of its metaphysical noise. It is in this purely semantic sense, also, that we may sometimes use the quid sit language rather than the an sit language in doing ontology. For instance, I would express my anti-realism about meanings by saying that I have not the faintest idea of what meanings are supposed to be. That would not be a profession of metaphysical ignorance. It would be a way of saying that I have no idea where to find such putative entities, and my anti-realist attitude would mainly follow from of the fact that none of the entities about which I have solid ontological intuitions fits any definition of 'meaning' offered by those linguists and philosophers of language who take meanings seriously (functional, non metaphysical definitions).

\section{An Optional Exercise}

So much for the first reply to the worry on the table: there is nothing incoherent in the thought that one could assert the existence of certain entities before embarking in metaphysical speculations concerning their ultimate nature. But I said that there is a second reply, and the second reply is that there is nothing incoherent even in the thought that we could limit ourselves to proclaiming our ontological credo without embarking at all in metaphysical speculations.

Consider what happens in mathematics. Most mathematicians would not hesitate to say (or to admit, if pressed) that they are serious about numbers - that numbers are indeed to be included in a good inventory of what there is as the truth-

makers of certain mathematical truths. Yet few would be willing to go further and say something committal about the nature of such truth-makers-to say what 
numbers really are. For most mathematicians, numbers are the referents of certain expressions and their fundamental properties are fixed by certain axioms-period. Surely one could go further, for example by insisting on the abstract nature of such entities: numbers are immaterial, have no spatio-temporal location, do not enter into causal interaction, etc. One could even be more precise. For instance, some would say that numbers are abstract individuals encoding exactly the mathematical properties they are supposed to have. ${ }^{14}$ Others might want to say that numbers are classes satisfying those properties, for instance cumulative sets $\grave{a}$ la Zermelo (as Alpha might put it: 0 is the empty set and every other number is the singleton of its immediate predecessor), or cumulative sets à la von Neuman (as Beta might insist: 0 is the empty set and every other number is the set of its predecessors). ${ }^{15}$ Surely there are several options out there. Still, it is a fact that mathematical practice does not require that we choose among those options: the choice is perceived by many as a pointless metaphysical question that is not worth the time (and here the term 'metaphysics' tends to acquire that negative connotation stigmatized by Carnap and the neopositivists ${ }^{16}$ ). What matters is not the nature of numbers but the principles that govern number theory. Well, then, if that is how things work in mathematics, one might hold a parallel view with regard to other contexts as well. Surely many biologists feel that way in regard to the metaphysical disputes on the nature of species, for instance. And the same may be said of any metaphysical dispute vis-à-vis a common ontological stance, including disputes over the metaphysics of ordinary objects. 'Surely statues are real things, but don't ask me what they are because I wouldn't know what to answer. I have never thought about that-and never will!' What truly matters - one could say - are the principles and laws that govern our favorite theories, whose truth depends on the existence of the entities they refer to or quantify over. Then one is free to go further and specify the metaphysical make-up of such entities. But that is an optional task, not a prerequisite for their legitimate inclusion in our inventory of the universe.

One could counter that this reply is open to a serious accusation: a philosopher that would just assert the existence of certain entities without saying what they are would be engaging in empty talk. In some domains, this complete severance between the an sit and the quid sit seems ludicrous: in saying that there are such things as quarks, for instance, a physicist has better explain what they are, otherwise her existential statement would be unintelligible. Why should it be different in math? More importantly, why should it be different in philosophy? To proclaim the existence of numbers, species, or statues whatever they are is ontologically uninformative. It is of no help whatsoever in drawing up a good inventory of the universe, as when Piglet and Pooh Bear insist that woozles exist but leave it at that. ${ }^{17}$ 
(There is also an epistemic variant of this complaint. For how can we know that something is 'unless we have some concept of that which we know to be', as Duns Scotus put it? [Ordinatio, I, d.3, q.2, schol.] Even Aquinas, in some texts, might be read as expressing caution in this regard, as when he wrote that we cannot know ourselves to possess chastity 'if we don't know what chastity is'. [De Veritate, q.10, ar.9, co.])

However, that is not quite the right way of putting it. As I mentioned, in the case of numbers we are not left entirely in the dark: whatever they are, numbers must enjoy a specific range of properties, say those properties that define the axiomatic corpus of Peano arithmetic. In saying that numbers exist, Alpha and Beta are committing themselves to the existence of entities that enjoy those properties. Their agreement is not empty. And their disagreement will only surface in regard to additional properties, properties that fall without the concerns of arithmetic, including those properties that reflect a precise metaphysical characterization of numbers (for instance, set-theoretic properties: according to Beta, the number 0 belongs to the number 2; non so for Alpha). Likewise, in the case of entities such as the statue of David there is a whole range of properties that such things are supposed to have in virtue of the application conditions, or "meaning postulates", that come with the correct use of the word 'statue' - properties such as having a certain origin, a certain purpose, perhaps a certain mass, and so on. Such postulates reflect a bunch of common-sense truths and do not, therefore, constitute a rigorous axiomatic theory comparable to arithmetic, but that is beyond the point. The point is that in asserting the existence of statues, say, both Alpha (an endurantist) and Beta (a perdurantist) are committing themselves to the existence of entities that enjoy such properties. ${ }^{18}$ It is simply not true that they do not attach any meaning to the word 'statue'. Their disagreement concerns certain additional properties (such as the possession of proper temporal parts) on which common sense says nothing at all and from which the correct use of the word 'statue' does not depend in the least. We could even say that precisely for this reason, as in the case of numbers, the disagreement between Alpha and Beta is "purely metaphysical". And if a third philosopher, Gamma, were to confine herself to saying that statues exist, thus agreeing with both Alpha and Beta while suspending judgment in regard to their disagreement, indeed without even addressing the challenge of further specifying the nature of statues, it would be unfair to complain that she is speaking empty words. At most, one could point out that spelling out her ontological credo does not exhaust the philosophical task of providing a comprehensive picture of what there is: a good philosopher should complete the picture by also spelling out the underlying metaphysics. ${ }^{19}$ 
One might still rejoin that the application conditions or meaning postulates associated with what I have called "common-sense truths", such as the postulates that fix the correct use of the word 'statue', are not metaphysically neutral: on the contrary, they would surreptitiously embody an inplicit "common-sense metaphysics" which even a philosopher such as Gamma would be embracing just by speak-

ing English. ${ }^{20}$ But I think this rejoinder would reflect a conception of the scope of metaphysics (in the sense in which I am using this term) that is simply too narrow. As already mentioned in regard to the word 'God', not any old property attribution contributes to a characterization of the metaphysical quid sit, and I would say that the attribution of those properties that are constitutive of our linguistic competence_precisely those properties that I am referring to when I speak of "meaning postulates", vague as this expression might be-contributes nothing at all. It merely serves the purpose of fixing the referent. Those attributes don't say what a thing is but only how it is, or rather what it is like. Otherwise we are back to the idea that in Michelangelo's mouth, the word 'water' referred to something else than what we call 'water' today. Worse, we would be led to the idea that natural language, or rather any given language, has its own metaphysics and ontology, and this would take us straight to the slippery slope of Whorfian relativism. ${ }^{21}$

Does it follow, then, that the ontology/metaphysics opposition rests implicitly on the analytic/synthetic distinction that so many of us have kicked away? ${ }^{22}$ No, it doesn't. It would follow, if the latter distinction went hand in hand with the distinction between what is constitutive and what is not constitutive of linguistic competence, as in Carnap. ${ }^{23}$ But there are beliefs that are constitutive of linguistic competence that could hardly be classified as analytic. For instance, anyone who can use the term 'statue' correctly will promtly assent to the truth of statements such as 'Statues are mute' or 'Statues don't fit into your wallet', but I would not say that such statements are analytic rather than synthetic. More generally, when a philosopher such as Gamma says 'There are $F$ s', the properties she attributes to the $F$ s are not just those properties $G$ such that 'The $F$ s are $G$ ' is an analytic truth, and it may well be that they do not even include all those properties (if such there be). ${ }^{24}$ The properties she attributes to the $F \mathrm{~s}$ are neither more nor less than those properties that we would find, if not in the dictionary, in a glossary entry for What's What. ${ }^{25}$

\section{Neutrality and Indeterminacy}

Pushing this line of thinking further, I would even say that the indeterminacy of a philosopher such as Gamma-the indeterminacy of an ontology without meta- 
physics - is not so different from other forms of indeterminacy that afflict much of our ordinary talk about the world. For instance, it is no news that ordinary language expressions can be vague; our linguistic practices have not fixed their meaning with absolute precision. Our lexicon includes predicates such as 'bald', even though we have not settled on a clear criterion for classifying each person as either bald or not bald. We have names or singular terms such 'Everest' or 'downtown Manhattan', even though we lack a precise criterion for drawing a boundary around their referents. It is that way because in ordinary circumstances such lack of precision is of no consequence. If, for example, we say that Everest is in Asia, our statement turns out to be true no matter how we suppose the relevant indeterminacy to be resolved: No matter how we suppose a precise boundary to be traced around the referent of 'Everest', subject to the constraints set by our linguistic practices, we would come up with an object that is located entirely in Asia. Well, then - the metaphysical neutrality of ontology may be understood along similar lines. Alpha and Beta agree in saying that the statue of David exists and is in Florence because this assertion is equally true on their respective conceptions (endurantist and perdurantist, for instance), provided the term 'statue' preserves all relevant semantic traits it has in English. And it is precisely for this reason that Gamma may even afford making the same existential assertion without taking a stance on those conceptions. No matter how the semantics of 'statue' is topped off with an explicit metaphysics - no matter how one resolves all residual indeterminacy concerning what statues really are - that existential assertion turns out to be true. (I would even say that claims about the existence of God admit of a similar explanation, at least in light of what I said above, so much so that many believers are content with the mere existential statement of their credo.)

To make the analogy with semantic vagueness more explicit, I am saying that the truth conditions of ontological claims obey the principles of a supervaluational semantics: ${ }^{26}$ the corpus of those truths that are presupposed by our ontological credo is defined by assertions that are metaphysically "super-true", i.e., true no matter how one specifies the metaphysical make-up of the entities referred to or quantified over by those assertions. Of course, in some cases this strategy does not pay off. For instance, the truth or falsity of a statement such as 'What you are now seeing is the current temporal part of Michelangelo's David' depends in a crucial way on the relevant metaphysics, exactly as the truth or falsity of a statement such as 'What you are now stepping on is part of Mount Everest' may depend in a crucial way on how we suppose a precise boundary to have been traced to fix the reference. Such statements are, for common sense, indeterminate, i.e., neither true nor false. But that should come as no surprise: it is precisely at this juncture that 
we find room for genuine metaphysical disagreement. What I am suggesting is that such a disagreement does not coincide with a dispute among different ontologies, and in some cases (or "for certain purposes", as some like to say) it can even be deemed irrelevant. It is necessary to specify an ontology in order to attach a meaning, however vague, to our statements; to spell out the underlying metaphysics is a task that is only needed to overcome any residual indeterminacy.

\section{Complications}

So much for the first part of the story: the main worry and my reply to it. Unfortunately, the story does not end here. As I mentioned, there are several further complications, and it is not clear to what extent such complications can be overcome without jepardizing the very idea of a sharp boundary between ontology and metaphysics. I will consider three distinct complications. ${ }^{27}$

The first concerns identity issues. Suppose that Gamma decides to go along with Alpha's metaphysics: statues are enduring entities, and likewise for any other material object. More: Gamma also agrees with Alpha that statues have certain essential properties that contribute to determining what they are. For instance, she agrees that the material constitution of a statue is an essential property: Had Michelangelo used a different piece of marble, the outcome would not have been David - the object whose existence is firmly asserted by Alpha and Gamma (and by Beta)_but a similar yet numerically distinct statue. At this point we ask for details concerning the relationship between the statue of David and the corresponding amount of marble and, mirabile dictu, we get different answers. Gamma says they are one and the same thing: the statue is the marble (the relation of material constitution being nothing but identity); Alpha says they are distinct (for instance, because they have different modal properties: throwing a stone would destroy the statue, not the marble; had Michelangelo left the job unfinished, the statue would not have existed while the marble would have been there; and so on). Now, not every identity dispute is metaphysically loaded; in many cases it is just a matter of figuring out the right interaction between sense and reference, as with the morning star and the evening star. But I take it as obvious that here the disagreement between Gamma and Alpha goes beyond language and falls squarely within the domain of metahysics: Gamma is a monist, Alpha a dualist. It is equally obvious, however, that such a disagreement immediately implies a disagreement at the ontological level: Alpha's inventory would include two items where Gamma only contains one. Indeed, in this connection the very idea that Gamma could steer away from all metaphysical troubles appears to be more problematic than I sug- 
gested above. Suspending any judgment on the identity or distinctness between the statue and the marble would yield an indeterminacy in the number of things, and this sort of indeterminacy can hardly be construed as a semantic issue.

A similar, but distinct problem arises in connection with reductionism issues. Suppose Delta is a philosopher for whom reality is at bottom constituted by all and only those entities that are posited by a certain scientific theory, say subatomic particles. Given the question 'Do statues exist?', Delta would not answer in the negative; she would say Yes, but she would hasten to clarify that statues, like any other macroscopic objects, are nothing over and above swarms of particles. (Delta is a reductionist, not an eliminativist.) Evidently, this sort of clarification pertains to the metaphysical sphere: it says what statues really are. Yet, again, its repercussions at the ontological level are immediate: someone who does not agree with Delta, i.e., a non-reductionist, would end up countenancing a larger number of distinct objects - statues and swarms of particles. They would agree on everything, yet their everythings would be distinct.

The third complication arises in connection with negative existential claims. Concerning statues and other ordinary objects, Delta is a reductionist, but when it comes to a whole range of putative entities postulated by her fellow philosophers, she is a firm eliminativist: there are no such things as species, numbers, meanings, or what have you. Plainly, such convictions pertain to the ontological sphere: they concern the question of what there is (or is not). Yet it is not clear how one could come to have convictions of this sort if not on the basis of some understanding of what species, numbers, meanings, etc., are supposed to be. In other words, and more generally, while it may be true that our positive beliefs about the denizens of world may be grounded in various ways, beginning with our direct experience of their reality, it's by no means clear how we could reach a negative ontological decision if not on the basis of some characterization of the putative entities whose existence we are going to deny. Now, there is no reason to suppose that every such characterization must belong to the metaphysical sphere. In order to deny the existence of winged horses, for instance, it suffices that I understand the concept of a winged horse, and this only requires that $\mathrm{I}$ be in possession of the basic application conditions or meaning postulates that govern the correct use of the predicates 'winged' and 'horse'. Arguably, one could say the same also in regard to philosophically more interesting candidates, such as numbers or meanings ${ }^{28}$ - in fact, I have said so already. My anti-realist attitude toward such things grew out of my coming to realize that none of the entities about whose existence I have solid evidence appears to match the definitions of 'meaning' or 'number' that I am aware of, and such definitions need not involve any serous metaphysics: they can be 
purely axiomatic (as with numbers) or functional (meanings). Still, Delta's eliminativism may not be entirely grounded on semantic postulates of this sort. At least in some cases, it may stem from a genuine metaphysical account - partial and approximate though it might be - of the nature of things. 'There are no such entities as meanings. For meanings are supposed to be abstract, and there are no abstract entities.' This is certainly a common way of putting things. And to the extent that it is a legitimate way, it lends evidence to the thought that at least in some cases metaphysics must come before ontology, not after. (Indeed, it would immediately follow from negative claims of this sort that even Delta's positive ontological claims are metaphysically loaded. For the claim that statues exist together with the claim that abstract entities do not exist entail that statues are not abstract-a claim that falls squarely within the domain of metaphysics.)

\section{To Be and Not to Be}

As I said, I am not sure whether such complications can be overcome without jepardizing the very idea of a sharp boundary between ontology and metaphysics, hence the priority thesis. But let me try.

To begin with, I will simply say that the first two complications - Is the statue something distinct from the marble? Is it something over and above a mere swarm of particles? - do not necessarily spell trouble for the ontology/metaphysics distinction. They would if we stuck to the popular idea, which I have hitherto endorsed, that to answer the ontological question What is there? is tantamount to drawing up a "complete inventory" of the universe. The inventory metaphor requires that we come to terms with issues of identity, for a good inventory ought to be exhaustive as well as non-redundant, i.e., it ought not to contain repetitions or double counting of any sort. As such, the task of drawing up a good inventory of the universe is soaked with metaphysical considerations. Strictly speaking, however, the ontological question does not require that much. To answer the question What is there? we have to come up with a list of what there is. Insofar as Gamma believes in the existence of statues, she would not object to a list that included statues, and insofar as she believes in the existence of marble pieces, she would not object to a list that included marble pieces. She might complain that a list that includes both, such as Alpha's, is redundant, because Gamma's monist metaphysics says that statues are marble pieces. But that's not to say that Gamma disagrees with anything that Alpha says in reply to the ontological question; their disagreement is metaphysical after all, not ontological. Likewise, insofar as Delta believes that statues are swarms of particles, she would not object to a list that included 
statues just as she would not object to a list that included swarms of particles. She might say that a list that includes both sorts of thing, such as Alpha's, is redundant, because Delta's reductionist metaphysics says that statues are swarms of particles. But that's not to say that Delta disagrees with anything that Alpha says in reply to the ontological question; once again, their disagreement is metaphysical, not ontological. In short, it is true that Alpha's ontology is more promiscuous than Gamma's or Delta's, but that is not the sense of 'ontology' that I've been focusing on: it stands for ontology as a theory, not as a sphere of inquiry. As a theory, any ontology should be metaphysically loaded; that is, after all, the point of Quine's precept, No entity without identity. ${ }^{29}$ But as a field of inquiry, we can still keep ontology separate from metaphysics. We just have to get rid of the inventory metaphor. (I would say the same when it comes to issues of identity that are not metaphysically loaded. For instance, if Alpha included in her inventory the morning star along with the evening star, she would not be doing a good job and we would be entitled to complain. Yet our complaint would be epistemic, not ontological. Drawing up a good inventory requires a great deal of empirical and theoretical knowledge just as it requires metaphysical sophistication, but these are obligations that go beyond the purview of the an sit question.)

As for the third complication-which I have illustrated through the case of negative existential claims - the picture is different. Here the challenge is serious and perhaps one should just bite the bullet and say that the priority thesis is hopeless. Indeed, there is a strong temptation to say that the thesis should be reversed: one must first attend to the metaphysical task of characterizing the nature of a variety of candidate entities and then figure out a way of telling which, among those candidates, truly exist. This was, after all, Meinong's idea, whereby any inquiry concerning the being so, or such-and-such, of a thing (its Sosein) has priority over the question of its being there (its Dasein). ${ }^{30}$ Nevertheless, there are two good reasons why I think this need only be a temptation - a temptation that one can and should avoid.

First, we can avoid it if we draw a more careful distinction between Aquinas's way of illustrating the task of ontology and Quine's more recent way, between the an sit question and the question What is there? So far I have been treating those questions as equivalent. However, there is an important difference. The an sit is dubitative: it is about whether a certain entity or type of entity exists. Aquinas was raising the question in regard to God, but we can certainly raise it also in regard to entities such as numbers, species, meanings, and so on. Since an answer to queries of this sort may be in the affirmative as well as in the negative, it follows that if we identify ontology with the an sit we end up having to deal, not only with the ques- 
tion 'What is there?', but also with the question 'What is not there?' Now, in itself neither question is in dubitative form. But while answering the second question triggers the complication that I have mentioned - the need for a preliminary metaphysical characterization-focusing exclusively on the first question, i.e., on Quine's question, need not involve any metaphysical work: we only have to be explicit about the motivations and methodology that lead us to acknowledge the existence of certain things - motivations and methodology which, as I have already said, may range widely and need not involve metaphysical considerations. So we must decide: ontology in Aquinas's sense, or ontology in Quine's narrower sense? It seems to me that, regardless of terminology, the second option is perfectly sufficient to capture the sense of ontology that matters the most. It is precisely because what matters is what there is that the inventory metaphor strikes us as prima facie adequate to characterize the task of ontology: an inventory is supposed to be a census of all citizens of the universe, not a register of all possible citizenship applications along with their respective verdicts. If so, then there is no need to reverse the order of the priority thesis. We can still say that ontology comes first. Indeed, we could even insist that the negative question, 'What is not there?', is ipso facto answered indirectly: after all, in answering Quine's positive question we are supposed to list everything. If none of the things in the list fulfills the definition of 'winged horse', then there are no winged horses. And if none of those things obeys to the laws of arithmetic, then there are no numbers. We just have to give up on the standard practice of spelling out our negative ontological credo directly, which is to say via negative existential claims, at least insofar as such claims involve a metaphysical characterization of the putative entities whose existence is being denied. Admittedly, this calls for some revision in the ordinary way of describing ontological disputes, but so be it. The practice is not the theory. (Thus, to go back to our example, Delta's eliminativism about meanings - insofar as it stems from their putative "abstract" nature-would be on a par with her reductionism about statues. Both would be genuine pieces of metaphysics, not metaphysically driven ontological tenets.)

Second, here is why I think that, not only we can, but we should resist the temptation of reversing the order between ontology and metaphysics. We should resist it because the reversal would justify a naive relativistic stance that we should better eschew. For suppose we accepted the view in question, according to which one can only figure out what there is on the basis of a comprehensive map of all the options - a map of all those categories or types of entity which are at least prima facie candidates to existence. The slogan would be: to decide what there is, one must first establish what there could conceivably be. Or: one should first fix 
the intension of all possible categories, and only afterward attend to the question of their actual extension. Now, obviously that would only work if the map of all the options were ontologically neutral, i.e., only if it did not fail to incorporate a category simply because we thought that it was empty. Otherwise we would be running in a circle. It is also obvious, however, that the idea of a map of categories that is completely neutral in this sense is wishful thinking. We can try as hard as we like, pushing our sense of immagination, our linguistic intuitions, our combinatorial dexterity, but what would ensure that the outcome would not betray biases and presuppositions that are mere evidence of our particular way of seeing things (if not of our culture and age, as already Collingwood put $\mathrm{it}^{31}$ )? The skeptic would not hesitate to protest than any method or criterion one might choose would only be one out of many equally legitimate methods or criteria, hence that any system of categories we might propose would just be a candidate among many others. And this would either give rise to an infinite regress or give in to the cheapest kind of relativism.

Besides - and finally - the very idea of an a priori system of categories that is truly comprehensive is wishful thinking, too. We know all too well how things have worked - or failed to work - in other fields of inquiry. ${ }^{32}$ When Marco Polo saw the rhinoceroses in Java, the best he could do was to classify them as unicorns. When the Aztecs hastened to the coast to witness the landing of the first conquistadores, they thought the Spaniards were riding deer because they could not think of a different sort of quadruped of that size. Not to mention the Australian colonists who first ran into that weird 'duck-billed' animal we now call the platypus. What sort of beast was that? Not a BIRD, in spite of the beak. Not a MAMMAL, because it laid eggs. And not a REPTILE, for its blood was warm. For over eighty years, naturalists from all over the world were baffled. Still in 1800 the German anatomist Johann Blumenbach came up with the name Ornithorynchus paradoxus. ${ }^{33}$ Not a good name, perhaps, but a telling one: one way or the other the beast was there but the category was missing. I see no reason why philosophers should think that the task of drawing up a complete system of categories should not run into the same problem. Surely we can always add a category that fits the bill - that it, the duckbill. But that is precisely the point: first comes the thing, then the category. First ontology, then metaphysics. Or perhaps just ontology and no metaphysics whatsoever. ${ }^{34}$ 


\section{Notes}

${ }^{1}$ The locus classicus is W. V. O. Quine, 'On What There Is', Review of Metaphysics, 2 (1948), 21-38. The "inventory" metaphor goes back to C. D. Broad, Scientific Thought, London: Routledge \& Kegan Paul, 1923, p. 242.

${ }^{2}$ This is, for instance, P. van Inwagen's use of the terms; see his 'The Nature of Metaphysics', in S. Laurence and C. Macdonald (eds.), Contemporary Readings in the Foundations of Metaphysics, Oxford: Blackwell, 1998, pp. 11-21, at p. 16.

${ }^{3}$ This is true, for instance, of philosophers working in the tradition of Roman Ingarden (Der Streit um die Existenz der Welt, Tübingen: Niemeyer, 1964, vol. 1, § 5), where metaphysics is the science concerned with making existential assertions about the different kinds of entity that ontology merely describes. See e.g. G. Küng, Ontologie und logistische Analyse der Sprache, Vienna: Springer, 1963.

${ }^{4}$ P. Benacerraf, 'What Numbers Could Not Be', Philosophical Review, 74 (1965), 47-73.

5 See e.g. D. Davidson, 'Events as Particulars', Noûs, 4 (1970), 25-32; R. M. Chisholm, 'Events and Propositions', Noûs, 4 (1970), 15-24; J. Kim, 'Events as Property Exemplifications', in M. Brand and D. Walton (eds.), Action Theory. Proceedings of the Winnipeg Conference on Human Action, Dordrecht: Reidel, 1976, pp. 159-177.

${ }^{6}$ More precisely: 'According to the laws of true logic [iuxta leges verce Logica] one must never ask if something exists [an sit] without knowing beforehand what it is [quid sit]' (Primae responsiones, 141).

${ }^{7}$ I have, for instance, been explicit on this in my book, Ontologia, Rome: Laterza, 2005.

${ }^{8}$ I am referring to H. Putnam, 'The Meaning of 'Meaning', Minnesota Studies in Philosophy of Science, 7 (1975), 131-193. See also the cats/robots example in his 'It Ain't Necessarily So', Journal of Philosophy, 59 (1962), 658-671.

${ }^{9}$ See e.g. P. Kitcher, 'Species', Philosophy of Science, 51 (1984), 308-333, and M. Ghiselin, 'A Radical Solution to the Species Problem', Systematic Zoology, 23 (1974), 536-544.

${ }^{10}$ H. E. H. Paterson, 'The Recognition Concept of Species', in E. S. Vrba (ed.), Species and Speciation, Pretoria: Transvaal Museum Monographs, 1985, pp. 21-29, at p. 22.

${ }^{11}$ See e.g. B. Smith and J. Searle, 'The Construction of Social Reality: An Exchange', American Journal of Economics and Sociology, 62 (2003), 285-309.

${ }^{12}$ K. Marx, Das Kapital: Kritik der politischen Ökonomie. Erster Band, Hamburg: Meissner, 1867, Ch. 1, § 4.

${ }^{13}$ A. J. Ayer, Language, Truth and Logic, London: Gollancz, 1936, ch. 6.

${ }^{14}$ See e.g. E. N. Zalta, 'Natural Numbers and Natural Cardinals as Abstract Objects: A Partial Reconstruction of Frege's Grundgesetze in Object Theory', Journal of Philosophical Logic, 28 (1999), 619-660.

${ }^{15}$ See E. Zermelo, 'Untersuchungen über die Grundlagen der Mengenlehre, I', $M a$ themathische Annalen, 65 (1908), 261-281, and J. Von Neumann, 'Zur Einführung der transfiniten Zahlen', Acta Universitatis Hungaricae Francisco-Josephinae. Sectio Scientiarum Mathematicarum, 1 (1923), 199-208. 
${ }^{16}$ R. Carnap, 'Uberwindung der Metaphysik durch logische Analyse der Sprache', Erkenntnis, 2 (1932), 219-241. Let me also quote from H. Mencken: 'A metaphysician is one who, when you remark that twice two makes four, demands to know what you mean by twice, what by two, what by makes, and what by four. For asking such questions metaphysicians are supported in oriental luxury in the universities, and respected as educated and intelligent men' (A Mencken Chrestomathy, New York: Knopf, 1949, pp. 13-14).

${ }^{17}$ The example is from A. A. Milne, Winnie-the-Pooh, London: Methuen, 1926, ch. 3.

${ }^{18}$ This is why the case at issue differs from other familiar cases, such as Argle and Bargle's celebrated dispute on holes (in D. K. Lewis and S. R. Lewis, 'Holes', Australasian Journal of Philosophy, 48 (1970), 206-212). When Argle concedes that holes exist, but are made of matter ('For every hole there is a hole-lining; for every hole-lining there is a hole. I say the hole-lining is the hole'; p. 207), I take it that he is not agreeing with Bargle's ontology, hence their dispute is not merely metaphysical. For Argle fails to comply with the meaning postulates that govern Bargle's ordinary use of the term 'hole': Bargle would never say that holes surround themselves, can be tasty, and so on; Argle would.

${ }^{19}$ Some might even insist that, pace Quine, the metaphysical part of the story is the only interesting one. See e.g. Shaffer, 'On What Grounds What', in D. J. Chalmers, D. Manley, and R. Wasserman (eds.), Metametaphysics. New Essays on the Foundations of Ontology, Oxford: Clarendon Press, 2009, pp. 347-383.

${ }^{20}$ See S. Nannini, 'Realismo scientifico e ontologia materialistica', Giornale di metafisica, 29 (2007), 483-496, spec. §4.

${ }^{21}$ See B. L. Whorf, Language, Thought, and Reality, Cambridge, MA: MIT Press, 1956.

${ }^{22}$ Following W. V. O. Quine, 'Two Dogmas of Empiricism', Philosophical Review, 60 (1951), 20-43.

${ }^{23}$ See R. Carnap, Meaning and Necessity. A Study in Semantics and Modal Logic, Chicago: University of Chicago Press, $1947 / 1956^{2}$.

${ }^{24}$ On this point I am indebted to an exchange with Diego Marconi. His book, Lexical Competence (Cambridge, MA: MIT Press, 1997), offers a full account of the notion of competence that I am assuming.

${ }^{25}$ That is, the counterpart of the familiar Who's Who devoted to those things that are not persons. See D. Fisher e R. Bragonier Jr., What's What. A Visual Glossary of the Physical World, Maplewood, NJ: Hammond, 1981.

${ }^{26}$ See K. Fine, 'Vagueness, Truth and Logic', Synthese, 30 (1975), 265-300.

${ }^{27}$ I will stick to the view that the notion of 'being', or 'existence', that defines the ontological question is univocal. Plainly, giving that up would generate additional complications for the priority thesis. But popular as that move might be, today as throughout the history of philosophy, I confess my inability to find it intelligible.

${ }^{28}$ See e.g. A. L. Thomasson, 'Answerable and Unanswerable Questions', in D. J. Chalmers, D. Manley, and R. Wasserman (eds.), Metametaphysics. New Essays on the Foundations of Ontology, Oxford: Clarendon Press, 2009, pp. 444-471, at pp. 453ff.

${ }^{29}$ W. V. O. Quine, 'Speaking of Objects', Proceedings and Addresses of the American Philosophical Association, 31 (1958), 5-22, at p. 20.

${ }^{30}$ See A. Meinong, 'Über Gegenstandstheorie', in A. Meinong, R. Ameseder, and E. 
Mally (eds.), Untersuchungen zur Gegenstandstheorie und Psychologie, Leipzig: Barth, 1904, pp. 1-50. More recently, the view that metaphysical investigations must precede ontological decisions has been endorsed - with varying terminology - by philosophers such as R. Grossmann (The Categorial Structure of the World, Bloomington, IN: Indiana University Press, 1983), R. M. Chisholm (A Realistic Theory of Categories, Cambridge: Cambridge University Press, 1996), A. L. Thomasson (Fiction and Metaphysics, Cambridge: Cambridge University Press, 1999), and E. J. Lowe (The Four-Category Ontology, Oxford: Clarendon, 2006).

${ }^{31}$ R. G. Collingwood, An Essay in Metaphysics, Oxford: Oxford University Press, 1940, at p. 11. See also S. Körner, Categorial Frameworks, Oxford: Basil Blackwell, 1974, and J. Westerhoff, Ontological Categories: Their Nature and Significance, New York: Oxford University Press, 2005, esp. Part II.

${ }^{32}$ The examples that follow come from H. Ritvo, The Platypus and the Mermaid, Cambridge, MA: Harvard University Press, 1997, and U. Eco, Kant and the Platypus, New York: Harcourt Brace and Company, 2000.

${ }^{33}$ J. F. Blumenbach, 'Einige anatomische Bemerkungen über den Ornithorhynchus paradoxus aus Neu-Südwallis', Magazin für den neuesten Zustand der Naturkunde mit Rücksicht auf die dazu gehörigen Hülfswissenschaften, 2 (1800), 284-291.

${ }^{34}$ A distant ancestor of this paper, in Italian, was delivered at the conference Ontologia e metafisica held at the Università del Piemonte Orientale, Italy, on January 12-13, 2007, and was published as 'Sul confine tra ontologia e metafisica', Giornale di metafisica, 29 (2007), 285-303. The current version is based on a paper prepared for the Conference on Ontology organized by The Logic and Cognitive Science Initiative of North Carolina State University (Raleigh, NC, September 25-26, 2009) and later delivered at colloquia at Indiana University Bloomington and at the Université de Genève, Switzerland. I am thankful to the participants in these events for their comments and reactionsespecially to Karen Bennett, Cameron Buckner, Cian Dorr, Gary Ebbs, David Fisher, Mark Heller, Philip Keller, Diego Marconi, Kevin Mulligan, Sandro Nannini, Laurie Paul, Luigi Perissinotto, David Sanford, Zoltán Gendler Szabó, and Peter van Inwagen. 